\title{
CATALYTIC ACTIVITY OF THE NOBLE METAL NANOPARTICLES
}

\author{
'Libor KVÍTEK, ${ }^{1}$ Tomáš STRYŠOVSKÝ, ${ }^{1}$ Martina KUBÍKOVÁ, ${ }^{1}$ Miroslav ORSÁG, ${ }^{1}$ Aleš PANÁČEK, \\ ${ }^{1}$ Robert PRUCEK
}

${ }^{1}$ Department of Physical Chemistry, Faculty of Science, Palacky University in Olomouc, Czech Republic, EU, libor.kvitek@upol.cz

https://doi.org/10.37904/nanocon.2020.3732

\begin{abstract}
Noble metal nanoparticles are excellent catalysts for many industrial important reactions. Because heterogenous catalysis is dependent strongly on the surface of catalyst the nanomaterials are better catalysts in comparison with the bulk materials. However, it is important for optimization of the effectivity of catalytic process to have a comparison of the nanostructured catalysts of different nature for application in the particular reaction. As a model for this process was conducted primary testing of catalytic activity of five noble metal nanoparticles $(\mathrm{Ru}, \mathrm{Rh}, \mathrm{Os}, \mathrm{Ir}, \mathrm{Pt})$ in redox reaction (reduction of 4-nitrophenol by the borohydride). It is interesting that for this model reaction the best catalyst is rhodium with the shortest induction period and fastest main part of the reaction course. On the other hand, platinum nanoparticles are not the best catalyst for the studied model reaction.
\end{abstract}

Keywords: Nanoparticles, noble metals, catalytic activity, model reaction, 4-nitrophenol

\section{INTRODUCTION}

Nanoparticles of metals, especially noble metals from the platinum group, show high catalytic activity with high potential for use in practical applications. Typically, these materials are tested as suitable catalysts for fuel cells [1]. These catalytic metals are currently difficult to replace in the redox reactions [2], but a similar situation prevails in the field of other types of catalytic reactions. Hydrogenations of unsaturated hydrocarbons can be mentioned as reaction mostly applicated in practice [3]. However, the catalytic action of this type of nanoparticles is also studied in other types of reactions - preparation of hydrogen by hydrolysis of ammonium borane [4] or in catalytic oxidation of organic compounds [5]. These metal nanocatalysts are frequently studied in reactions useful in environmental technologies [6]. In this respect, they are involved in a number of studies where a model reaction is used to assess their basic catalytic activity. Typically, the most used model reaction is reduction of 4-nitrophenol to 4-aminophenol. [7].

Preparation of nanoparticles of these noble metals is most easily accomplished by the method of chemical reduction of a salt of a given metal using a suitable reducing agent. When $\mathrm{NaBH}_{4}$ is used as a reducing agent, the smallest particles in the range of about $1.5-5 \mathrm{~nm}$ are formed for all metals in this group $[1,8]$. However, since the metal nanoparticles prepared by this method easily aggregate, they are stabilized using protective layers formed by surfactants [9] or polymers [7,10]. Stabilization ca be also realized by anchoring of nanoparticles on the surface of a solid inert substrate of the type of carbonaceous materials [3] or inorganic substances such as $\mathrm{ZnO}$ [11]. On the other way, the reducing action of weak reducing agents, as are polyols, are often used in this field [2,12]. Due to the highly positive redox potential of noble metal ions, the so-called "green synthesis", which has recently become very popular, using natural substances as reducing agents and stabilizers of the resulting nanoparticles, can also be used in the preparation of this type of nanoparticles. Thus, for example, Pd nanoparticles can be prepared by reduction with polyphenols from black tea extract. [13] 
However, very few studies can be found in the available literature offering a basic comparison of the catalytic activity of platinum metal nanoparticles prepared by the same method in the same standard reaction. Therefore, this study is aimed at platinum metal nanoparticles which were prepared using reduction synthesis with $\mathrm{NaBH}_{4}$ and then they were tested for their catalytic activity in the most commonly used model reaction reduction of 4-nitrophenol with $\mathrm{NaBH}_{4}$.

\section{EXPERIMENTAL}

\subsection{Chemicals}

The chemicals that were used for the preparation of nanoparticles and subsequent kinetic experiments are listed in Table 1. Deionized water (18 $\mathrm{M} \Omega \cdot \mathrm{cm}$, Millipore) was used to prepare all solutions.

Table 1 Chemicals for nanoparticle preparation and kinetics experiments

\begin{tabular}{cccc}
\hline Formulae & Name & Producer & Molar weight $(\mathrm{g} / \mathrm{mol})$ \\
\hline $\mathrm{NaBH}_{4}$ & Sodium borohydride & Sigma-Aldrich & 37.83 \\
$\mathrm{C}_{6} \mathrm{H}_{5} \mathrm{Na}_{3} \mathrm{O}_{7} \cdot 2 \mathrm{H}_{2} \mathrm{O}$ & Trisodium citrate dihydrate & Lach-Ner & 294.1 \\
$\mathrm{RuCl}_{3} \cdot \mathrm{xH}_{2} \mathrm{O}$ & Ruthenium(III) chloride hydrate & Merck KGaA & 207.43 \\
$\mathrm{RhCl}_{3} \cdot 3 \mathrm{H}_{2} \mathrm{O}$ & Rhodium(III) chloride trihydrate & Merck KGaA & 263.32 \\
$\mathrm{PdCl}_{2}$ & Palladium(II) chloride anhydr. & Sigma-Aldrich & 177.33 \\
$\mathrm{OsCl}_{3} \cdot \mathrm{xH}_{2} \mathrm{O}$ & Osmium(III) chloride hydrate & Sigma-Aldrich & 296.59 \\
$\mathrm{IrCl}_{3} \cdot \mathrm{xH}_{2} \mathrm{O}$ & Iridium(III) chloride hydrate & Merck KGaA & 298.58 \\
$\mathrm{PtCl}_{4}$ & Platinum(IV) chloride & Merck KGaA & 336.89 \\
$\mathrm{C}_{6} \mathrm{H}_{5} \mathrm{NO}_{3}$ & 4-nitrophenol & Lachema & 139.11 \\
\hline
\end{tabular}

\subsection{Nanoparticles preparation}

Nanoparticles of all metals used in this study were prepared in the same way - reduction of a salt of a given metal with borohydride and citrate. Citrate also serves as a stabilizer of the resulting nanoparticles. The reaction takes place at room temperature. In a $50 \mathrm{ml}$ beaker, mix $5 \mathrm{ml}$ of $\mathrm{NaBH}_{4}$ solution with a concentration of $10^{-2} \mathrm{~mol}_{\mathrm{dm}} \mathrm{d}^{-3}$ and $5 \mathrm{ml}$ of sodium citrate solution with a concentration of $2.10^{-2} \mathrm{~mol}_{\mathrm{dm}} \mathrm{dm}^{-3}$ while stirring. To the solution is then added water to obtain total volume $20 \mathrm{ml}$ and then left to stand for about 20 minutes. Subsequently, $5 \mathrm{ml}$ of a $4.96 .10^{-3} \mathrm{~mol}^{-\mathrm{dm}^{-3}}$ salt solution of the metal are added dropwise. The reaction is stopped after stirring for another about 20 minutes.

\subsection{Nanoparticles characterization}

The resulting colloidal dispersions were characterized by UV-Vis spectroscopy and the dynamic light scattering (DLS, Zetasizer Nano ZS, Malvern Instruments, UK) method. However, the particle sizes measured by DLS were taken as indicative only, and the actual particle size was determined only from transmission electron microscope images (TEM, JEM 2100, Jeol Ltd., Japan). UV-Vis spectra (Specord S600, Analytic Jena AG, Germany) were obtained after 10 -fold dilution of resulting dispersions. 


\subsection{Catalytic experiments}

For the purpose of evaluating the catalytic activity of the prepared nanoparticles, a solution of 4-nitrophenol with a concentration of $1.5 .10^{-3} \mathrm{~mol}^{-\mathrm{dm}^{-3}}$ was prepared, which was used in all experiments. The $\mathrm{NaBH}_{4}$ solution $\left(8.10^{-3} \mathrm{~mol} \mathrm{dm}^{-3}\right)$ was prepared fresh before each experiment due to its considerable instability. The reaction system was prepared by mixing $0.03 \mathrm{ml}$ of the prepared nanoparticle dispersion, $0.09 \mathrm{ml}$ of 4-nitrophenol (4NP) solution and $1.28 \mathrm{ml}$ of water. A cuvette with this solution was placed in a UV-Vis spectrophotometer (Specord S600, Analytic Jena AG, Germany), the measurement being started immediately after the addition of $1.6 \mathrm{ml}$ of $\mathrm{NaBH}_{4}$ solution. The $\mathrm{NaBH}_{4}$ solution must be allowed to stand for 20 minutes after preparation so that the kinetic experiment takes place at a time when its reducing power is the best. All measurements were performed in a quartz cuvette in the wavelength range of $250-600 \mathrm{~nm}$. The duration of the experiment was set to 20 minutes, measured every 10 seconds.

\section{RESULTS AND DISSCUSSION}

\subsection{Nanoparticles preparation}

Noble metal nanoparticles prepared by the above reduction method were characterized by UV-vis spectroscopy and their size was evaluated from TEM images (Figure 1). The one same procedure was used to prepare nanoparticles of all platinum metals with the exception of palladium, whose nanoparticles in the given method of preparation quickly aggregated and the resulting aggregates sedimented to the bottom of the reaction vessel. Because the aim of this study was to evaluate the catalytic activity of unmodified metal nanoparticles, no attempt was made to stabilize these nanoparticles with surfactants or polymers that can fundamentally affect the resulting catalytic activity [14]. In all cases, a strong absorption peak in the region of 190-210 nm appeared in the UV-vis spectra (Figure 2), which is typical for very small platinum metal nanoparticles. [link below] The average size of the prepared nanoparticles is given in Table 2.

Table 2 Average size of the prepared nanoparticles (measured in nanometers)

\begin{tabular}{ccccc}
\hline Ruthenium & Rhodium & Osmium & Iridium & Platinum \\
\hline $5.1 \pm 1.1$ & $4.8 \pm 1.3$ & $1.3 \pm 0.6$ & $1.2 \pm 0.3$ & $4.4 \pm 1.3$ \\
\hline
\end{tabular}

Except for iridium, whose dispersion was yellow, all the dispersions prepared were in shades of brown, and except for iridium and osmium, the dispersions were color stable. The iridium dispersion began to change color from yellow to light blue approximately one week after preparation. The reason for this color change is probably the recrystallization of nanoparticles. The dispersion of osmium was changed the intensity of color over time, this color change is observable about three weeks after preparation. The reason is probably the deposition of nanoparticles on the walls of the vessel.

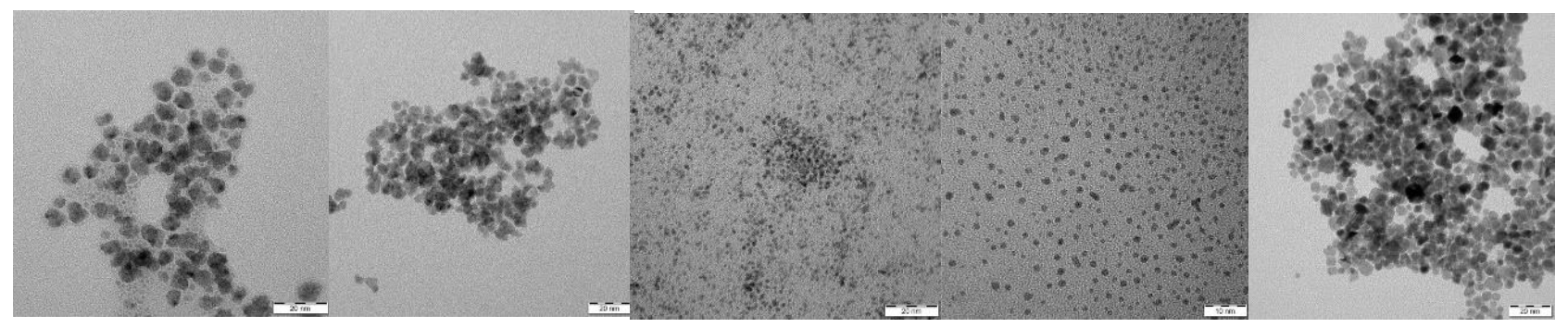

Figure 1 TEM images of nanoparticles a) Ru, b) Rh, c) Os, d) Ir, e) Pt (scale is $20 \mathrm{~nm}$, only for Ir $10 \mathrm{~nm}$ ) 


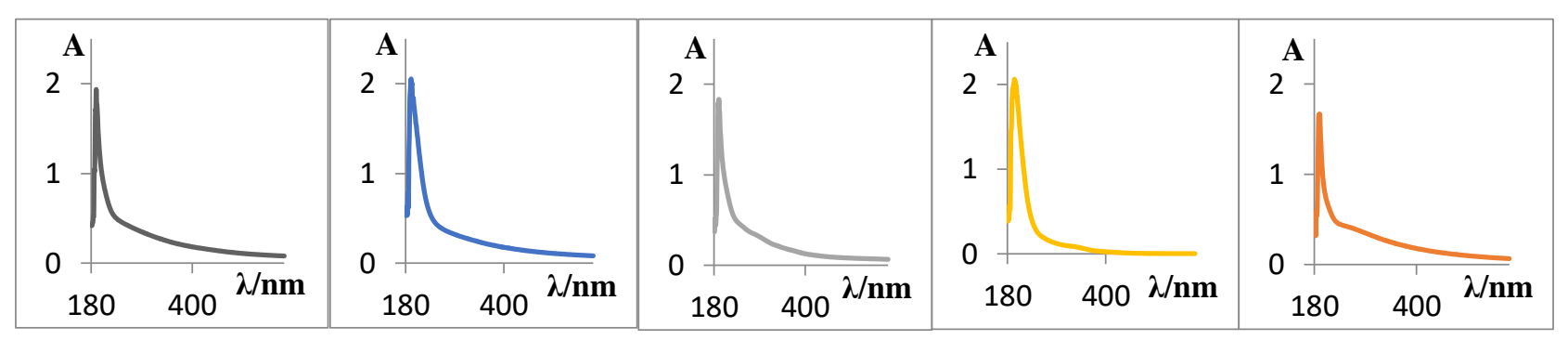

Figure 2 UV-vis spectra of aqueous dispersions of nanoparticles a) Ru, b) Rh, c) Os, d) Ir, e) Pt

\subsection{Catalytic activity of nanoparticles}

The catalytic activity of the prepared nanoparticles was studied using a model reaction, which was the reduction of 4-Nitrophenol (4-NP) to 4-Aminophenol. 4-Nitrophenol has a significant absorption peak at 401 $\mathrm{nm}$, which decreases with reduction and a new peak appears around $300 \mathrm{~nm}$, which belongs to 4-aminophenol. Since reductant $\mathrm{NaBH} 4$ is in significant excess, it was possible to evaluate the used model reaction according to the kinetics of the pseudo-first order. For this reason, it was possible to subtract the rate constants as exponents in absolute value from the exponential regression equation from the graphs of the absorbance of 4-nitrophenol versus time. Absorbance values at $401 \mathrm{~nm}$ were used for this evaluation. When calculating the value of the rate constant, only the time interval in which the value of the logarithm of the absorbance decreased linearly was used from the graph of the dependence of the logarithm of absorbance on time. Thus, the time interval corresponding to the initiation period, in which the catalyst surface is activated in a strongly reducing environment and the primarily adsorbed particles are replaced by reactant molecules, was omitted from the calculation. To evaluate the effect of this slow part of the reaction, the reaction half-times $t 1 / 2$ were also subtracted from the measured kinetic curves, which better reflect the overall course of the catalytic reaction. The records of the spectra from the catalytic experiments are shown in Figure 3.

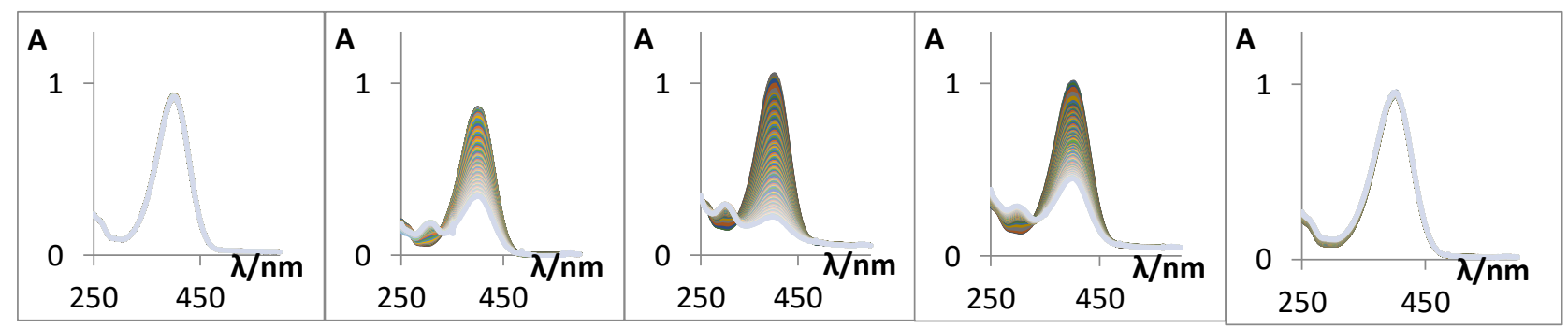

Figure 3 UV-vis spectra taken from the catalytic reaction of 4-NP reduction by borohydride a) without catalyst, b) catalysis of RuNPs, c) RhNPs, d) OsNPs, e) PtNPs, f) IrNPs

The average value of the rate constant for the reaction catalysed by ruthenium nanoparticles was the same as for the reaction catalysed by rhodium nanoparticles. However, the very long time was required to activate the Ru nanoparticle surface caused the reaction to be generally slower than in the case of Rh. This fact is also evidenced by the average value of the reaction half-time, which is almost 2.5 times higher for Ru than for $\mathrm{Rh}$ (Table 3).

As was already mentioned, the average value of the rate constant for the reaction catalysed by ruthenium nanoparticles is the same as in the case of $R u$, but due to the much shorter time required for its activation, the reaction is faster. As a result, $R$ h nanoparticles (in this study) proved to be the best catalyst. A similar result was obtained in the study of Maegawa et al. [3].

The average value of the rate constant of the reaction catalysed by osmium nanoparticles makes it the third best catalyst. Iridium nanoparticles have proven to be the worst catalyst and the reaction catalysed by them practically does not run, even compared to the uncatalyzed reaction. These nanoparticles appear to be an 
inhibitor of the observed reaction. However, the probable cause of a slight increase in absorbance (approximately $2 \%$ ) is rather influenced by the aggregation of iridium nanoparticles in the reaction system. Platinum nanoparticles have proven to be the second worst catalyst in the reaction system used, but unlike other metals, this catalyst shows no initiation period.

Table 3 Rate constants and reaction half-times of 4-nitrophenol reduction with $\mathrm{NaBH}_{4}$ in the presence of noble metal nanocatalysts

\begin{tabular}{|c|c|c|c|c|c|c|c|c|c|}
\hline \multirow{2}{*}{$\begin{array}{c}\text { Metal } \\
\text { Ruthenium }\end{array}$} & \multicolumn{6}{|c|}{ Rate constants $\left(\mathrm{s}^{-1}\right)$} & $\mathrm{k}_{\mathrm{av}}\left(\mathrm{s}^{-1}\right)$ & \multirow{2}{*}{$\frac{k_{\mathrm{S}}\left(\mathrm{s}^{-1}\right)}{0.0004}$} & \multirow{2}{*}{$\frac{t_{1 / 2 a v}(s)}{1250}$} \\
\hline & 0.001 & 0.001 & 0.001 & 0.002 & 0.002 & 0.001 & 0.0013 & & \\
\hline Rhodium & 0.001 & 0.001 & 0.002 & 0.002 & 0.001 & 0.001 & 0.0013 & 0.0004 & 485 \\
\hline Osmium & 0.0005 & 0.0006 & 0.0006 & 0.0005 & 0.0006 & 0.0004 & 0.00053 & 0.0001 & 1275 \\
\hline Platinum & 0.0002 & 0.0003 & 0.0002 & 0.0002 & 0.0003 & 0.0003 & 0.00025 & 0.00005 & 2990 \\
\hline
\end{tabular}

$\mathrm{k}_{\mathrm{s}}$ - rate constants normalised per $1 \mu \mathrm{g}$ of catalyst

$t_{1 / 2 a v}$ - reaction half-times obtained from the experimental kinetic curves (evaluated as average from six measurements)

\section{CONCLUSION}

The presented study was focused on methods of preparation of noble metal nanoparticles and study of their catalytic activity. The objective was to compare catalytic activity of these nanoparticles for redox reactions. Metal nanoparticles were prepared by the same method using sodium borohydride as primary reducing agent in the presence of sodium citrate as secondary reducing agent and stabilizer of the prepared nanoparticles. Successfully was prepared nanoparticles of ruthenium with an average diameter of $5.1 \mathrm{~nm}$, nanoparticles of rhodium with an average diameter of $4.8 \mathrm{~nm}$, nanoparticles of osmium with an average diameter of $1.3 \mathrm{~nm}$, nanoparticles of iridium with an average diameter of $1.2 \mathrm{~nm}$ and nanoparticles of platinum of average size 4.4 $\mathrm{nm}$. Palladium nanoparticles wasn't involved in this work because of problems with their preparation. The catalytic activity of the prepared nanoparticles was studied using model reaction based on reduction of 4nitrophenol to 4-aminophenol with sodium borohydride at room temperature. Rate constants for reactions catalysed by nanoparticles of each metal were calculated using pseudo-first order kinetics. Rhodium nanoparticles have proven to be the best catalyst. Although the reaction catalysed by ruthenium nanoparticles had the same average rate constant as the reaction catalysed by rhodium nanoparticles, the very long time was required for activation of Ru catalyst. By this reason, ruthenium nanoparticles were worse catalyst than rhodium nanoparticles. Osmium nanoparticles were the third best catalyst. The second worst catalyst were platinum nanoparticles. The worst catalyst were iridium nanoparticles, which had no catalytic activity in the used reaction system.

\section{ACKNOWLEDGEMENTS}

The authors acknowledge financial support from ERDF project "Development of pre-applied research in nanotechnology and biotechnology" (No. CZ.02.1.01/0.0/0.0/17_048/0007323), and from Internal Grant of Palacky University in Olomouc (IGA_PrF_2020_034).

\section{REFERENCES}

[1] LUO, M., YANG, Y., GUO, S. Precious metal nanocrystals for renewable energy electrocatalysis: structural design and controlled synthesis. Dalton Transaction. 2020, vol. 49, pp. 267-273. 
[2] QUINSON, J., INABA, M., NEUMANN, S., SWANE, A.A., BUCHER, J., SIMONSEN, S.B., KUHN, L.T., KIRKENSGAARD, J.J.K., JENSEN, K.M.O., OEZASLAN, M., KUNZ, S., ARENZ, M. Investigating Particle Size Effects in Catalysis by Applying a Size-Controlled and Surfactant-Free Synthesis of Colloidal Nanoparticles in Alkaline Ethylene Glycol. ACS Catalysis. 2018, vol. 8, pp. 6627-6635.

[3] MAEGAWA, T., AKASHI, A., YAGUCHI, K., IWASAKI, Y., SHIGETSURA, M., MONGUCHI, Y., SAJIKI, H. Efficient and Practical Arene Hydrogenation by Heterogeneous Catalysts under Mild Conditions. Chemistry: an European Journal. 2009, vol. 15, pp. 6953-6963.

[4] AKBAYRAK, S., ÖZÇIFÇI, Z., TABAK, A. Noble metal nanoparticles supported on activated carbon: Highly recyclable catalysts in hydrogen generation from the hydrolysis of ammonia borane. Journal of Colloid and Interface Science. 2019, vol. 546, pp. 324-332.

[5] SO, M-H., HO, C-M., CHEN, R., CHE, C-M. Hydrothermal Synthesis of Platinum-Group-Metal Nanoparticles by Using HEPES as a Reductant and Stabilizer. Chemistry: an Asian Journal. 2010, vol. 5, pp. 1322-1331.

[6] ANANTHARAJ, S., NITHIYANANTHAM, U., EDE, S.R., AYYAPPAN, E., KUNDU, S. m-stacking intercalation and reductant assisted stabilization of Os organosol for catalysis. RSC Advances. 2015, vol. 5, pp. 11850-11860.

[7] CUI, Y., LIANG, B., ZHANG, J., WANG, R., SUN, H., WANG, L., GAO, D. Polyethyleneimine-stabilized palladium nanoparticles for reduction of 4-nitrophenol. Transition Metal Chemistry, 2019. vol. 44, pp. 655-662.

[8] ANANTHARAJ, S., JAYACHANDRAN, M., KUNDU, S. Unprotected and interconnected Ru0 nano-chain networks: advantages of unprotected surfaces in catalysis. Chemical Science. 2016, vol. 7, pp. 3188-3205.

[9] SEO, J., LEE, S., KOO, B., JUNG, W-C. Controlling the size of Pt nanoparticles with an cationic surfactant, CnTABr. CrystEngComm. 2018, vol. 20, pp. 2010-2015.

[10] LIEW, K.H., ROCHA, M., PEREIRA, C., PIRES, A.L., PEREIRA, A.M., YARMO, M.A., JUAN, J.C., YUSOP, R.M., PEIXOTO, A.F., FREIRE, C. ChemCatChem. 2017, vol. 9, pp. 3930-3941.

[11] DEMILLE, T.B., HUGHES, R.A., PRESTON, A.S., ADELUNG, R., MISHRA, Y.K., NERETINA, S. Light-Mediated Growth of Noble Metal Nanostructures ( $\mathrm{Au}, \mathrm{Ag}, \mathrm{Cu}, \mathrm{Pt}, \mathrm{Pd}, \mathrm{Ru}, \mathrm{Ir}, \mathrm{Rh}$ ) From Micro- and Nanoscale ZnO Tetrapodal Backbones. Frontiers in Chemistry. 2018, vol. 6, Article 411.

[12] FU, J., WANG, S., WANG1, X., YAN, Y., WANG, K., GAO, M., XU, Q. Facile preparation of highly dispersed Pt nanoparticles supported on heteroatom-containing porous carbon nanospheres and their catalytic properties for the reduction of 4-nitrophenol. Journal of Porous Materials. 2018, vol. 25, pp. 1081-1089.

[13] LEBASCHI, S., HEKMATI, M., VEISI, H. Green synthesis of palladium nanoparticles mediated by black tea leaves (Camellia sinensis) extract: Catalytic activity in the reduction of 4-nitrophenol and Suzuki-Miyaura coupling reaction under ligand-free conditions. Journal of Colloid and Interface Science. 2017, vol. 485, pp. $223-231$.

[14] NEAL, R.D., HUGHES, R.A., SAPKOTA, P., PTASINSKA, S., NERETINA, S. Effect of Nanoparticle Ligands on 4-Nitrophenol Reduction: Reaction Rate. ACS Catalysis. 2020, vol. 10, pp. 10040-10050. 